\section{Promoting dialogue is the best way to combat ID in classrooms}

SIR - Even after more than a century of vindication for evolutionary biology, creationism remains a stubborn problem for science educators.

In your Editorial "Dealing with design" (Nature 434, 1053; 2005) and News Feature "Who has designs on your students' minds?" (Nature 434, 1062-1065; 2005), theistic scientists were asked to discuss how they reconcile their faith with science. Atheistic scientists were asked to take the time to understand matters of faith and how they relate to theories and findings of modern science. I applaud these recommendations, but it seems many of my colleagues do not.

"The issue will not go away if we ignore the challenge posed by ID." - Herman L. Mays Jr

In the Correspondence letter from Jerry Coyne, co-signed by many of the most prominent figures in biology ( ${ }^{\alpha}$ When science meets religion in the classroom ${ }^{x}$ Nature 435 , $275 ; 2005)$, this approach is rejected. Rather than expressing the neutrality of science on matters of religion, I think this letter epitomizes the disregard, if not outright hostility, towards religious faith that is all too common in the scientific community.

This refusal to discuss what some students perceive as the threat posed by evolution, and the idea that science classrooms are the place where religious views "crumble", will only result in science teachers having to deal more with 'intelligent design' (ID) in the future.

I do not want to discuss religion in the science classroom any more than Jerry Coyne does, but the issue will not go away if we simply ignore the challenge posed by ID and the concerns - albeit misguided - of students. Increased student dialogue and sensitivity on the part of instructors are exactly what is called for, to combat the inroads made by ID into the science classroom.

\section{Herman L. Mays Jr}

Department of Biological Sciences,

Auburn University, Auburn, Alabama 36849, USA

\section{Science and religion can strengthen each other}

SIR - I was rather disappointed with the one-sided presentation of intelligent design theory in your News Feature (Nature 434, $1062-1065 ; 2005)$, and even more so with the Correspondence letters (Nature 435, 275-276; 2005). They take the naive viewpoint that religious and scientific thought must be in conflict. That is not the only, in fact not even (historically) the most prevalent, mode of addressing these two important subjects.

Most of the founding fathers of western science had no difficulty reconciling their religious beliefs with their scientific pursuits. In fact, the latter grew out of the former. This discussion actually goes back as far as the writings of Thomas Aquinas and the early Greek philosophers. Some of their writings on the interplay between these two fields is far more 'modern', thoughtful and relevant than much published in the modern age.

As a Christian and a scientist, I have continually found that one method of pursuing knowledge complements the other. Any conflicts I have are resolved by the revelation of my errors of thought in one area or the other. Thus my scientific reasoning bolsters my faith while my religious reasoning augments my scientific pursuits.

If one believes in objective truth and is using a rational system of thought (and when properly applied, both scientific and religious thought meet these two criteria) there is no need to feel threatened by another's pursuit of truth. In the worst case, the two groups can agree to disagree, but in the best case they can learn more about truth together, through respectful dialogue, than they can separately.

The relationship between science and religion needs attention at a fundamental level. Only if both sides sincerely try to understand each other can a mutually beneficial dialogue be resumed. Philip C. Farese

Department of Physics, Princeton University, Princeton, New Jersey 08544, USA

\section{Thoughtful peer review is worth the time it takes}

SIR — I read with surprise Steve Donovan's comment, in Correspondence, that it took him "less than an hour" to review a paper ("Reviewers not attached to online submission" Nature 434, 956; 2005). I am not sure if this included typing up the referee's report, but this seems a very short time indeed when it may have taken the authors a year to write the paper in the first place.

I am no expert in palaeontology, and maybe the paper Donovan refereed was relatively easy to assess. But I often have the impression when receiving referees' reports on my work, both favourable and negative, that they were also compiled in "less than an hour". I spend too long refereeing manuscripts - often a full week-end or more - and sometimes end up writing excessively long reports. But I need that much time to check the cited literature, perform calculations or try to interpret the data in a (generally) less fashionable way than the authors did.

Mistakes can be made by any referee, whether quick or slow, but in my experience the revised version of an article usually benefits from more thoughtful exchanges.

I agree with Donovan that we should not make the refereeing process unnecessarily difficult. But, as it is the only way to prevent false results or erroneous daims being published, we should not reduce it to a trivial act.

\section{Xavier Michalet}

Department of Chemistry and Biochemistry, University of California, Los Angeles, Los Angeles, California 90095-1569 USA

\section{Despite some flaws, online submission is the future}

\section{SIR - John P. Moore, in Correspondence,}

laments the increased burden placed on scientists by the many journals that use an electronic submission system ("Online submission makes authors do all the work" Nature 433,$800 ; 2005)$. It is true that the online system requires manuscripts to be prepared to the journals' specifications. For some journals it goes beyond spacing or file formats to seemingly minor details such as the format and font of the citations in text, footnotes and tables, and even the number of pixels for the figures. It's a lot of effort for first-time users, unless they are lucky enough to find someone experienced to help them. I can also imagine the problem it poses for scientists without access to all the technology.

Nonetheless, I feel strongly that the advantages of this system far outweigh the deficiencies. I can remember, twenty years ago, submitting copies of typed manuscripts by airmail from Taiwan to Europe or North America, which routinely cost half a day's pay. I usually had to wait for a month or two to receive an acknowledgement. If I had heard nothing after three months, I would send a letter of inquiry and wait another month or so to hear if it had been received. On more than one occasion manuscripts were lost in the post and had to be sent again. Queries (in either direction) and revised manuscripts were no less vulnerable to such mishaps. Compared with this, receiving an immediate acknowledgement and being able to track progress and submit a revised manuscript online is pure heaven.

Having said that, I feel improvements can still be made. Journals could help by allowing the flexible use of the most widely used and least expensive file formats for submission. Letting authors use an edit-friendly format, rather than having to do all the formatting themselves, would increase their motivation to submit papers. Given the ever-rising cost of journals, this would be only reasonable. Ying-Hen Hsieh

Department of Applied Mathematics, National Chung Hsing University, 250 Kuo-Kuang Road, Taichung, Taiwan 402 